\title{
Spontaneous Life Threatening Massive Retroperitoneal and Iliopsoas Hemorrhages in Adult Hemophilia - A Patients with Inhibitor - Case Series
}

\author{
Najmaddin Khoshnaw ${ }^{1 *}$, Belal A. Muhammad ${ }^{2}$ and Ahmed k. Yassin ${ }^{3}$ \\ ${ }^{1}$ Department of Hematology, Hiwa Hospital, Sulaymaniyah, Kurdistan Region, Iraq \\ ${ }^{2}$ Department of Medical Laboratory Techniques, Technical Institute of Halabja, Sulaimani Polytechnic University, Sulaymaniyah, Kurdistan Region, Iraq \\ ${ }^{3}$ Program Director of clinical hematology Board KBMS, Hawler Medical University, medical college, Erbil, Kurdistan Region, Iraq
}

*Corresponding author: Najmaddin Khoshnaw, Department of Hematology, Hiwa Hospital, Sulaymaniyah, Kurdistan Region, PO. Box: 54 at Al-Sulaymaniyah Post Office, Iraq, Tel: +964 (0) 7701554184; E-mail: najmaddin_salih@yahoo.com

Received date: Feb 09, 2015, Accepted date: Mar 18, 2015, Publication date: Mar 21, 2015

Copyright: (c) 2015 Khoshnaw N, et al. This is an open-access article distributed under the terms of the Creative Commons Attribution License, which permits unrestricted use, distribution, and reproduction in any medium, provided the original author and source are credited.

\begin{abstract}
Spontaneous retroperitoneal and iliopsoas muscle hemorrhages are rare bleeding episodes in hemophilia patients. Their diagnosis requires high degree of clinical suspicion because presentation may mimic other abdominal and pelvic disorders. These bleedings in severe hemophilia-A patients with factor VIII inhibitor are associated with high morbidity and mortality as control of hemostasis in these cases is challenging.

Herein we report 4 adult patients with known congenital Hemophilia-A and factor VIII inhibitor. One of the patients had gigantic retroperitoneal hemorrhage presented with subsequent increase in abdominal pain. The other three patients had significant iliopsoas hemorrhage presented with groin pain. All the events were spontaneous and nontraumatic. These patients were treated with recombinant activated factor VII ( $\mathrm{rFVIla)}$ in a dose of $90 \mu \mathrm{g} / \mathrm{kg}$. Treatment with rFVIla has significant favorable outcome and all the patients had dramatic response to the treatment and discharged safely from the hospital after 7-10 days of admission. Patients with iliopsoas hemorrhage showed persistent femoral nerve neuropathy. The rarity and spontaneous bleeding episodes at presentation are crucial points for reporting these cases.
\end{abstract}

Keywords: Hemophilia-A; rFVIIa; Factor VIII inhibitor; Retroperitoneal haemorrhage; Iliopsoas hemorrhage

\section{Background}

Retroperitoneal hemorrhage (RPH) is simply defined as bleeding into retroperitoneal space and occasionally on examination appears as bruising of the flank called gray-turner's sign. Spontaneous intraabdominal (retroperitoneal and iliopsoas) hemorrhages are rare bleeding episodes that may happen in cases of congenital coagulation disorders including Hemophilia-A, Hemophilia-B, and Von well brand disease [1-3]. Reports about this kind of bleeding and their management are still limited. However, other causes of spontaneous $\mathrm{RPH}$ are well defined in the literature such as rupture of retroperitoneal organs, aneurysm of major blood vessels, drugs (antithrombotic, anti-platelets, and fibrinolysis therapy), tumors (adrenal, kidneys or secondary metastatic invasion), iatrogenic as hemodialysis or it may be idiopathic [4-16].

The pathophysiology of the spontaneous RPHs is unclear. It may be related to the atherosclerotic changes $[17,18]$, or it may be due to stretching of sheath of the intra-abdominal muscles by physical efforts such as coughing which usually postulated in cases of severe Hemophilia $[2,5,19,20]$.

Patients with RPH and iliopsoas muscle hemorrhages (ISH) usually have spontaneous vague abdominal pain localized to flanks, loin, or lower back, and some time to the groin or iliac fosse. The later condition may be associated with paraesthesia and numbness over the site of the distribution of the femoral nerve (anterior thigh and lumber region indicating femoral nerve neuropathy).There will be also difficulty in extending hip joint (thigh usually remain flexed and externally rotated) due to iliopsaos muscle spasm. This is due to nerve pressure or ischemia by hematoma inside muscle sheath [9,18,21-23].

Diagnosis of spontaneous RPH and ISH usually starts with clinical suspicion; which depends on the underlying diseases such as in congenital Hemophilia. However, ultrasonography, computed tomography (CT) scan, and magnetic resonance imaging (MRI) are remained the important diagnostic tools in these group of patients $[24,25]$.

Inhibitor formation in these patients is a major problem and can cause serious complications especially in case of severe HA. Inhibitors are antibodies formed secondary to exogenous factor replacement and occasionally to endogenous FVIII. Its incidence is higher in HA than Hemophilia-B, and higher in pre-treated patients, increasing with age [26]. It has been found that around $23-33 \%$ of patients with severe HA will develop inhibitor formation secondary to repeated factor replacement. However, in moderate and mild cases of FVIII deficiency, the incidence is lower [26,27].

In term of management, patients who developed inhibitors should be treated for bleeding and also to eliminate the inhibitor level. In early eighties, specialists used plasma derived factor VII for patients with high titer of inhibitor to FVIII [26]. Since then, many other factors have been developed such as recombinant activated factor VIIa (rFVIIa) (NovoSeven). rFVIIa is a bypassing factor which induces thrombin generation and the formation of a stable fibrin plug [26]. This factor is usually used for controlling the bleeding episodes in adults with severe HA and inhibitor especially those who undergo 
Citation: Khoshnaw N, Muhammad BA, Elmeshhedany A (2015) Spontaneous Life Threatening Massive Retroperitoneal and lliopsoas Hemorrhages in Adult Hemophilia - A Patients with Inhibitor - Case Series. J Blood Disorders Transf 6: 261. doi: $10.4172 / 2155-9864.1000261$

Page 2 of 6

surgical operation $[26,28]$. Treatment with bypassing factors such as rFVIIa or prothrombin complex concentrates usually have supportive roles in such cases [29].

Many studies have indicated the safety and efficacy of rFVIIa and showed that it can be safely used in patients receiving concomitant antifibrinolytic agents [25,30-32]. In addition, the use of rFVIIa has also been approved by the FDA in the USA [33]. The usual dose of $\mathrm{rFVIIa}$ is $90 \mu \mathrm{g} / \mathrm{kg}$ every $2-4$ hours. However, some studies showed that a single administration of a higher dose of $270 \mu \mathrm{g} / \mathrm{kg}$ of rFVIIa is equally efficacious and has a similar safety profile [34-36]. It has been also reported that a single dose of rFVIIa is effective and well tolerated in the treatment of intra-articular bleeds in patients with Hemophilia complicated by the presence of inhibitors [37].

\section{Case Report}

Written informed consent was obtained from all individual participants included in the study. All the relevant clinical and laboratory observations for all the patients with congenital Hemophilia are shown in Table 1.

\begin{tabular}{|c|c|c|c|c|}
\hline Relevant clinical features & Patient 1 & Patient 2 & Patient 3 & Patient 4 \\
\hline Age at presentation & 22 & 21 & 26 & 46 \\
\hline Presenting symptom & $\begin{array}{l}\mathrm{RT}^{\mathrm{a}} \text { loin pain extending to } \mathrm{RT}^{\mathrm{a}} \\
\text { iliac fosse }\end{array}$ & $\begin{array}{l}\mathrm{RT}^{\mathrm{a}} \text { lower abdominal } \\
\text { pain }\end{array}$ & Right iliac fosse pain & Lower backache \\
\hline Duration of pain in days & 5 & 2 & 2 & 4 \\
\hline Factor VIII level at diagnosis & $<1 \%$ & $<1 \%$ & $4 \%$ & $<1 \%$ \\
\hline $\mathrm{HB}^{\mathrm{b}}$ & $5.6 \mathrm{gm} / \mathrm{dl}$ & $9.7 \mathrm{gm} / \mathrm{dl}$ & $11 \mathrm{gm} / \mathrm{dl}$ & $11.4 \mathrm{gm} / \mathrm{dl}$ \\
\hline$W B C^{c}$ & $12 \times 10^{*} 6$ & $6.6 \times 10^{*} 6$ & $12 \times 10^{*} 6$ & $12.9 \times 10^{*} 6$ \\
\hline Platelets & $221 \times 10^{*} 6$ & $333 \times 10^{*} 6$ & $300 \times 10^{*} 6$ & $429 \times 10^{*} 6$ \\
\hline $\mathrm{aPTT}^{\mathrm{d}}$ & 92 seconds & 88 seconds & 55 seconds & 75 seconds \\
\hline Duration of stay & 10 days & 9 days & 7 days & 7 days \\
\hline Size of hematoma & $150 \times 120 \times 100 \mathrm{~mm}$ & $250 \times 96 \times 85 \mathrm{~mm}$ & $160 \times 70 \times 60 \mathrm{~mm}$ & $180 \times 34 \mathrm{~mm}$ \\
\hline Site of hemorrhage & $\begin{array}{l}\mathrm{RT}^{\mathrm{a}} \text { side of abdomen } \\
\text { retroperitoneal hematoma }\end{array}$ & $\begin{array}{l}\mathrm{RT}^{\mathrm{a}} \text { side of pelvis } \\
\text { extending to loin region }\end{array}$ & $\mathrm{RT}^{\mathrm{a}}$ sided iliacus(ileopsoas) muscle & $\begin{array}{l}\text { RT side retroperitoneal psoas } \\
\text { muscle hematoma }\end{array}$ \\
\hline
\end{tabular}

Table 1: The relevant clinical and laboratory features of all patients with congenital hemophilia.

\section{Case 1}

In April 2012, a 22-years-old man with congenital severe hemophilia-A, who was on-demand factor VIII replacement, was refereed to hematology department. The patient was complaining of gradually increasing severe right side abdominal pain radiating to the back and right loin region for 5 days pre-admission. On admission, the patient was in shock state, having tachycardia and tachypnea. His physical examination showed huge abdominal distension, more prominent on the right side with bluish discoloration of the right flank, swelling and ecchymosis of the right testis. Scrotum was enlarged and tender on palpation, decreased air entry on the right lower part of chest. The patient was urgently resuscitated with supportive treatments.

Laboratory investigations showed prolonged aPTT (activated partial thromboplastin time) $92 \mathrm{~s}$ (reference range: 28-38), which was not corrected via mixing with an equal volume of normal plasma (mixing study). The lab results also showed that the inhibitor titer was $20 \mathrm{IU} / \mathrm{L}$ (Bethesda unit), his factor VIII activity was less than $1 \%$ (reference range: 50\%-150\%), his hemoglobin was $5.6 \mathrm{gm} / \mathrm{L}$, hematocrit $17 \%$ and $\mathrm{RBC}$ count of $1.96 \times 10^{12} / \mathrm{L}$ as shown in Table 1 . An urgent ultrasonography showed multiple heterogeneous masses in the right side of the abdomen measuring $120 \times 140 \mathrm{~mm}$ with active bleeding. Moreover, a large fluid collection was found in the left side, retroperitonealy, with possibility of active bleeding and upper ureter dilatation due to pressure effects as shown in Figure 1A.

The plane chest X-ray showed elevation of the right dome of the diaphragm (Figure 1B) and the CT scan with intravenous contrast showed large $(150 \times 120 \times 100 \mathrm{~mm})$ right side retroperitoneal heterogeneous space occupying lesion (hematoma). This lesion filled almost all the space of the right side of the abdomen and pelvis. Furthermore, this hematoma was associated with fat stranding in the retroperitoneal region displacing bowel loops to the contra lateral side (Figure 1C and 1D). We promptly started rFVIIa administration in a dose of $90 \mu \mathrm{g} / \mathrm{kg}$ every 2 hours. The patient received six units of blood with sufficient antibiotic coverage, analgesia and transexamic acid. The patient remained in the hospital for 10 days. Neutrophilia, thrombocytosis and few nucleated red cells found on his blood film on discharge. 
Citation: Khoshnaw N, Muhammad BA, Elmeshhedany A (2015) Spontaneous Life Threatening Massive Retroperitoneal and lliopsoas Hemorrhages in Adult Hemophilia - A Patients with Inhibitor - Case Series. J Blood Disorders Transf 6: 261. doi: $10.4172 / 2155-9864.1000261$

Page 3 of 6
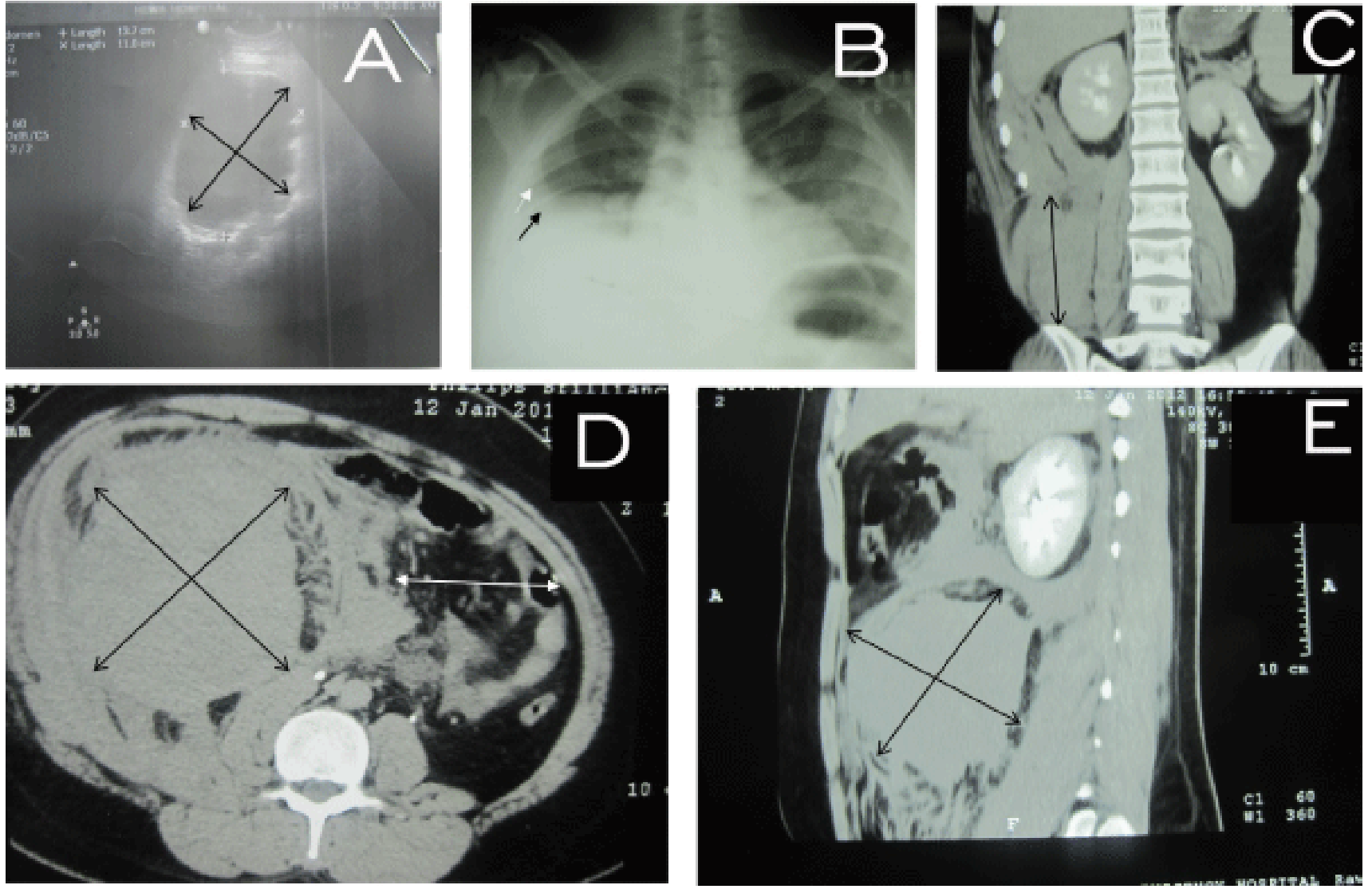

Figure 1: A) Ultrasound of abdomen, in 22 years old man showing large hematoma (double arrows). B) Plane X-ray shows elevation of the RT dome of diaphragm (black arrow) with mild plural fusion (white arrow). C) CT scan show large hematoma in the right side of abdomen pushing the right kidney laterally. D and E) CT scan with intravenous contrast show large $150 \times 120 \times 100 \mathrm{~mm}$ right side retroperitoneal heterogeneous space occupying lesion (double arrows). The haemotoma was almost occupied the right side of the abdomen and pelvis associated with fat stranding in the retroperitoneal region. D) The mass was displacing bowel loops to the contra lateral side with contrast features of RPH (white double arrow).

\section{Case 2}

A 21-year-old male who was a known case of congenital severe hemophilia-A on on-demand factor VIII replacement therapy, presented to the casualty department in January 2013, complaining of right lower abdominal pain for 24-hours duration. The patient was initially seen by an orthopedic surgeon and he diagnosed the case as hip joint osteoarthritis.

The patient had spent one day in the hospital during which the pain gradually increased with radiation to the groin and back aggravated by extension of the right thigh. The pain was associated with sweating, dizziness, pallor, and dyspnoea. He has no history of trauma, drug use, or other chronic diseases. Finally, this patient was referred to our department by the orthopedist.

On admission, we found that the patient was in pain, pale, have tachycardia, and high temperature $\left(38.5^{\circ} \mathrm{C}\right)$. On systemic examination, there was tender swelling in the right side of the abdomen extending to the right groin. The patient was also seen with a bilateral knee join swelling with inability to extend the joints (old advanced osteoarthritis change). Other systemic examinations were unremarkable.
Initial investigations showed moderate hypochromic microcytic anemia as shown in Table 1 . The ultrasonography of the abdomen and pelvis showed large right sided pelvic collection about $(200 \times 80 \times 70$ $\mathrm{mm}$ ) extending to the right loin region (Figure 2A). The aPTT was prolonged to 88 seconds (reference range: 28-38) and it was not corrected via mixing with normal plasma indicating presence of inhibitor.

Then we obtained the titer of the inhibitor which was 19 IU/L (Bethesda unit). The CT scan of the abdomen and pelvis showed heterogeneous mass of $(250 \times 96 \times 85 \mathrm{~mm})$ which was not enhanced by contrast, and retroperitoneal in the right side of psoas muscle (Figure 2B-2D).

The patient was resuscitated by giving intravenous fluid, analgesia, factor rFVIIa ( $90 \mu \mathrm{g} / \mathrm{kg}$ every 2 hours) and one unit packed RBC. He remained on treatment for 9-days in the hospital then discharged home with persistent paraesthesia. 
Citation: Khoshnaw N, Muhammad BA, Elmeshhedany A (2015) Spontaneous Life Threatening Massive Retroperitoneal and lliopsoas Hemorrhages in Adult Hemophilia - A Patients with Inhibitor - Case Series. J Blood Disorders Transf 6: 261. doi: $10.4172 / 2155-9864.1000261$

Page 4 of 6
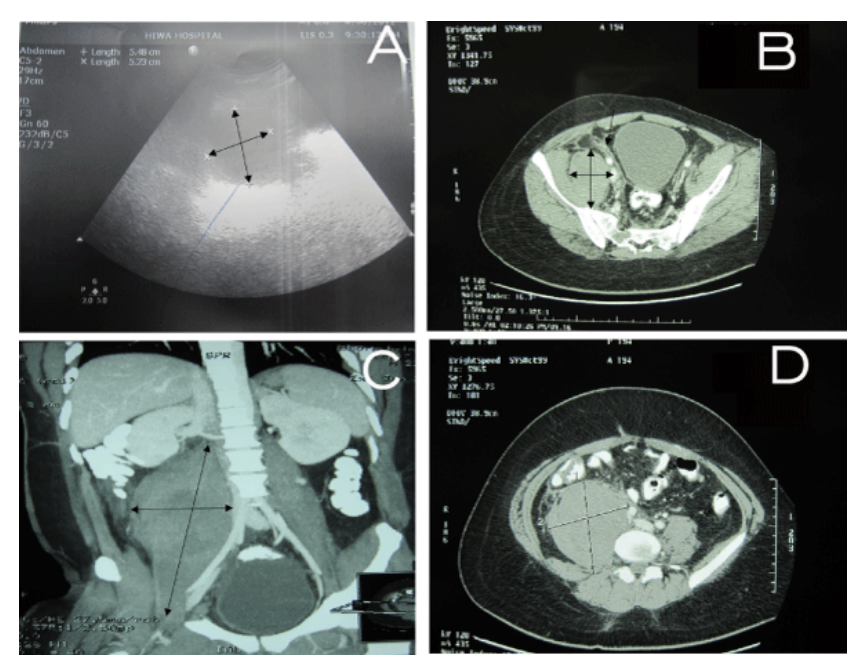

Figure 2: A) Ultrasound showed large right sided pelvic collection about $200 \times 80 \times 70 \mathrm{~mm}$ (double arrows) extending to the right loin region. $\mathrm{B}, \mathrm{C}$, and $\mathrm{D}) \mathrm{CT}$ scan of the abdomen and pelvis showed heterogeneous mass of $250 \times 96 \times 85 \mathrm{~mm}$ (double arrows in B and $\mathrm{C}$, lines in D) not enhanced by contrast retroperitoneal in the right side of psoas muscle.

\section{Case 3}

A 26-years-old man with congenital Hemophilia-A and factor VIII inhibitor, was presented with right lower abdominal pain and tenderness for 2-days duration. This patient has been previously treated by on-demand replacement therapy.

The patient was not able to extend his right leg associated with paraesthesia of the thigh. Laboratory investigations presented in Table 1 showed moderate anemia with neutrophilia indicated by CBP. The patient's inhibitor titer was $13 \mathrm{IU} / \mathrm{L}$ (Bethesda unit) and his aPTT was prolonged to $55 \mathrm{~s}$ (reference range: 28-38), which has not been corrected by mixing study.

The ultrasound showed ill-defined solid heterogeneous mass measured $210 \times 80 \mathrm{~mm}$ involving iliopsoas muscle down to insertion. The mass was avascular on color Doppler study and showed features of intramuscular hematoma with scanty amount of free peritoneal fluid (Figure 3A).

The CT scan showed large non-enhancing heterogeneous swelling extending along the whole right side iliacus muscle measuring about $160 \times 70 \times 60 \mathrm{~mm}$ (Figure 3B). The patient was treated with conservative treatment with rFVIIa in a dose of $90 \mu \mathrm{g} / \mathrm{kg}$, every 2-4 hours. The patient was well managed and discharged after 7 days. However, he was still suffering from femoral nerve neuropathy.
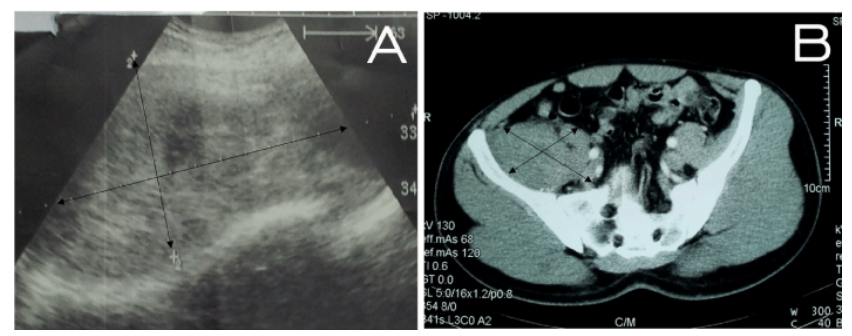

Figure 3: A) Ultrasound examination of the patient with large iliopsoas hematoma. B) CT scan showed large non-enhancing heterogeneous swelling extending along the whole right side iliacus muscle measuring about 160 x70 $\times 60 \mathrm{~mm}$ (double arrows).

\section{Case 4}

In June-2013, a 46-years-old man with known hemophilia-A was presented to Hiwa hospital with right loin pain and fever for 4-days duration. The pain was associated with difficulty in walking and extension of the right thigh and it was radiating to back and groin. The patient was initially seen by an orthopedist and based on the MRI, was diagnosed as an acute disc prolapse. The patient had a history of lower backache and renal stone as well.

After admission to our hospital, we did ultrasonography which showed a large $(94 \times 70 \mathrm{~mm})$ retroperitoneal hematoma along the psoas muscle. After $100 \%$ factor VIII elevation the aPPT was not corrected and still $88 \mathrm{~s}$, the inhibitor titer was $25 \mathrm{IU} / \mathrm{L}$ (Bethesda unit) and the bleeding was progressive. The hematoma was increased in size as indicated by CT scan (Figure 4A-4C). We found the right side retroperitoneal psoas muscle hematoma seen anteriorly all over the muscle measuring about $186 \times 34 \mathrm{~mm}$. On the peripheral blood film, we found a mild to moderate hypochromic microcytic anemia with high red cell distribution width and mild thrombocytosis indicating blood loss (Table 1).

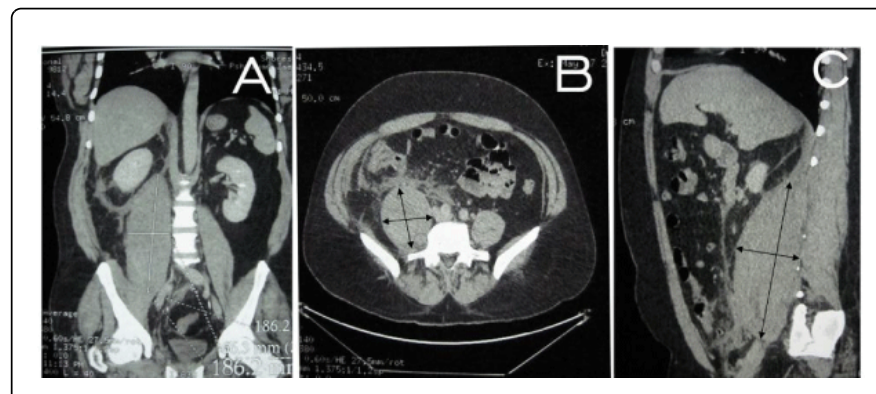

Figure 4: A-C) CT scan showed right side retroperitoneal psoas muscle hematoma seen anteriorly all over the muscle $(186 \mathrm{~mm}$ length $\times 34 \mathrm{~mm}$ width) (lines and double arrows).

We gave aggressive treatment including rFVIIa in a dose of 90 $\mu \mathrm{g} / \mathrm{kg}$ every two hours for 5 days with transexamic acid, complete rest, and analgesia. Eventually, we could successfully control the bleeding and discharge the patient on day seven of his admission. 
Citation: Khoshnaw N, Muhammad BA, Elmeshhedany A (2015) Spontaneous Life Threatening Massive Retroperitoneal and lliopsoas Hemorrhages in Adult Hemophilia - A Patients with Inhibitor - Case Series. J Blood Disorders Transf 6: 261. doi: $10.4172 / 2155-9864.1000261$

Page 5 of 6

\section{Discussion}

Herein we present the cases of four adult patients with known congenital hemophilia-A, that have different clinical presentations and different initial diagnosis. The median age of these patients were 23years ranging between 21-46 years as shown in Table 1.

The surgical approach in non-Hemophilia patients with RPH has been thoroughly discussed in the literature [22,38]. However, studies about use of bypassing factors such as rFVIIa for treatment of hemophilic patients are still limited and, to our knowledge, have not been reported in Iraq so far. Therefore, reporting the case series of these patients, for the first time in Iraq, is particularly important as it is going to help clinicians in the region to set and optimize their treatment protocol more efficiently.

It has been widely accepted that patients with Hemophilia-A especially the severe and moderate types are more liable for inhibitor formation [39]. It is also well known that different factors play roles in inhibitor development such as genetic mutations, ethnic background, increases with age, and treatment-related previous exposure days [40-43]. Indeed, our cases who were treated by $>50$ exposure days are supporting this notion.

Some of the above factors might be the cause of inhibitor formation in our patients and made them present more aggressively and spontaneously in a way that was not easy to be controlled by conventional treatment. There is no literature published data in Iraq about the frequency of inhibitor in hemophilia patients, but according to the local data from Erbil and Baghdad there is lower incidence of inhibitor to factor VIII in compare to other western countries. But the aggressive behavior and serious hemorrhage in our patient need more explanation however ethnic background may have role in our Kurdish patients. This was more pronounced in the first case which has a huge spontaneous RPH (Figure 1) with a subsequent increase in abdominal pain. Such gigantic RPH is rarely reported worldwide and its treatment is extremely difficult. However, we could successfully treat our hemophilic patients with rFVIIa and obtain dramatic hemostatic results using the proposed standard dosage and timing $(90 \mu \mathrm{g} / \mathrm{kg}$ of rFVIIa every 2-4 hours until the bleeding was stopped) [39]. As we were surrounded by lots of limitations, this can be considered as a great achievement for our hospital.

The median age of presentation of aggressive bleedings in our study was 23 years involving those patients that were exposed to periods of sanctions including the Gulf war on Iraq at the beginning of 1991. These patients were undertreated and received on demand treatment. The rarity and severity of spontaneous retroperitoneal bleeding and the vague clinical presentation made the diagnosis and management more difficult and led to initial miss diagnosis of some cases including patient number 2 and 4 in the current study. In our patients, the symptoms were generally appeared as an acute onset with slow progression and persistent pain in inguinal, lower abdominal quadrant, or lumbar region radiating to the scrotum and groin region. In last three cases, sever pain and paresthesia was found in the anterior, lateral, and medial aspect of thigh and leg especially along the line of distribution of femoral nerve (L2, 3 and 4) as in the case 2-4 due to the pressure effect of different size of hematomas (Figures 2-4).

All patients had dramatic response to the treatment plan described above and discharged safely from the hospital. Patients with iliopsoas hematoma had persistent femoral nerve neuropathy. Unlike ordinary patients, the bleeding in our patients was enormous, progressive and defied simple rules of Hemophilia management. In such cases, we and others found that the ultrasonography and CT scan were very helpful and made the diagnosis easy [42,43]. Moreover, we noticed that the $\mathrm{RPH}$ and ISH of all patients was occurred in the right side for no obvious reasons. This could be related to anatomical site or other unknown factors. Furthermore, we found neutrophilia in three patients and thrombocytosis in two patients. The mean of their initial hemoglobin count was $8 \mathrm{gm} / \mathrm{dl}$ ranging from 5.6 to $11.4 \mathrm{gm} / \mathrm{dl}$ as shown in Table 1. Two patients were required to have red cell transfusion for managing their symptomatic anemia and shock. All the patients have been treated and discharged after correction of their hemoglobin, aPTT, and the hemodynamic status to a normal level. Bleeding was stopped and the size of hematoma (hemorrhage) was decreased.

Finally, we believe that the outcome of this study is very important for the medical community and further highlight successful management of unusual cases of hemophilia. The study also supports the previous claims that the early diagnosis and supportive treatment with use of rFVIIa is crucial and successful in saving the life of hemophilic patients.

\section{Acknowledgement}

We would like to thank the ministry of health of Kurdistan region (Dr. Rekawt Ham-Rasheed), Dr. Anwar Sheikha and the director of Sulaymaniyah health directorate (Dr. Meran M.) and manager of the Hiwa hospital (Dr. Dosti Najat Othman), Dr. Sana Dlawar assistant professor of hemato-patholgy in sulaymaniyah central laboratory for interpreting the inhibitor tests, also we have special thanks to all medical and laboratory staffs, patients and families of the patients in helping us for collecting the data.

\section{Author Contribution}

NK has managed and diagnosed the cases of the patients, write most parts of the manuscript, BAM designed, wrote and corrected most parts of the article, AKY shared in writing and reviewing most parts of the manuscript with writing the literature review.

\section{References}

1. Eby CS, Caracioni AA, Badar S, Joist JH (2002) Massive retroperitoneal pseudotumour in a patient with type 3 von Willebrand disease. Haemophilia 8: 136-141.

2. Ylmaz, S, Oren H, Irken G, Atabay B, Duman M, et al. (2005) Lifethreatening mediastinal-retroperitoneal hemorrhage in a child with moderate hemophilia A and high inhibitor titer: successful management with recombinant activated factor VII. J Pediatr Hematol Oncol 27: 400-4002.

3. Jones JJ, Kitchens CS (1984) Spontaneous intra-abdominal hemorrhage in hemophilia. Arch Intern Med 144: 297-300.

4. Abu-Zidan FM, Jawas A, Boraie M, Ahmed MU (2011) Delayed retroperitoneal bleeding causing acute abdominal compartment syndrome: case report. Ulus Travma Acil Cerrahi Derg 17: 183-185.

5. Berná JD, Zuazu I, Madrigal M, García-Medina V, Fernández C, et al. (2000) Conservative treatment of large rectus sheath hematoma in patients undergoing anticoagulant therapy. Abdom Imaging 25: 230-234.

6. Bhasin HK, Dana CL (1978) Spontaneous retroperitoneal hemorrhage in chronically hemodialyzed patients. Nephron 22: 322-327.

7. Daliakopoulos SI, Bairaktaris A, Papadimitriou D, Pappas P (2008) Gigantic retroperitoneal hematoma as a complication of anticoagulation therapy with heparin in therapeutic doses: a case report. J Med Case Rep 2: 162 
Citation: Khoshnaw N, Muhammad BA, Elmeshhedany A (2015) Spontaneous Life Threatening Massive Retroperitoneal and lliopsoas Hemorrhages in Adult Hemophilia - A Patients with Inhibitor - Case Series. J Blood Disorders Transf 6: 261. doi: $10.4172 / 2155-9864.1000261$

Page 6 of 6

8. Ernits M, Mohan PS, Fares LG 2nd, Hardy H 3rd (2005) A retroperitoneal bleed induced by enoxaparin therapy. Am Surg 71: 430-433.

9. Fernandez-Palazzi F, Hernandez SR, De Bosch NB, De Saez AR (1996) Hematomas within the iliopsoas muscles in hemophilic patients: the Latin American experience. Clin Orthop Relat Res 328: 19-24.

10. Gullà N, Patriti A, Capitanucci L, Fabbri B, Patriti A, et al. (2000) A case of "silent" pheochromocytoma presenting as spontaneous retroperitoneal hematoma. Ann Ital Chir 71: 735-737.

11. Machuca Santa Cruz J, Julve Villalta E, Galacho Bech A, Pérez Rodríguez D, Quiñonero Díaz A, et al. (1999) [Spontaneous retroperitoneal hematoma: our experience]. Actas Urol Esp 23: 43-50.

12. Mant MJ, O'Brien BD, Thong KL, Hammond GW, Birtwhistle RV, et al. (1977) Haemorrhagic complications of heparin therapy. Lancet 1: 1133-1135.

13. Monib S, Ritchie A, Thabet E (2011) Idiopathic retroperitoneal hematoma. J Surg Tech Case Rep 3: 49-51.

14. Rapp N, Audibert G, Gerbaud PF, Grosdidier G, Laxenaire MC (1994) [Spontaneous retroperitoneal hematoma: a rare cause of hemorrhagic shock]. Ann Fr Anesth Reanim 13: 853-856.

15. Vos CG, Hoksbergen AW (2011) Fatal retroperitoneal bleeding caused by metastasis of a sigmoid carcinoma. Case Rep Med 2011: 373047.

16. Won DY, Kim SD, Park SC, Moon IS, Kim JI (2011) Abdominal compartment syndrome due to spontaneous retroperitoneal hemorrhage in a patient undergoing anticoagulation. Yonsei Med J 52: 358-361.

17. Qanadli SD, El Hajjam M, Mignon F, Bruckert F, Chagnon S, et al. (1999) Life-threatening spontaneous psoas haematoma treated by transcatheter arterial embolization. Eur Radiol 9: 1231-1234.

18. Torres GM, Cernigliaro JG, Abbitt PL, Mergo PJ, Hellein VF, et al. (1995) Iliopsoas compartment: normal anatomy and pathologic processes. Radiographics 15: 1285-1297.

19. Arbini AA, Mannucci PM, Bauer KA (1995) Low prevalence of the factor V Leiden mutation among "severe" hemophiliacs with a "milder" bleeding diathesis. Thromb Haemost 74: 1255-1258.

20. Aronstam A, McLellan DS, Turk P (1979) Transfusion requirements of adolescents with severe haemophilia A. J Clin Pathol 32: 927-930.

21. Goodfellow J, Fearn CB, Matthews JM (1967) Iliacus haematoma. A common complication of haemophilia. J Bone Joint Surg Br 49: 748-756.

22. Nobel W, Marks SC Jr, Kubik S (1980) The anatomical basis for femoral nerve palsy following iliacus hematoma. J Neurosurg 52: 533-540.

23. Parmer SS, Carpenter JP, Fairman RM, Velazquez OC, Mitchell ME (2006) Femoral neuropathy following retroperitoneal hemorrhage: case series and review of the literature. Ann Vasc Surg 20: 536-540.

24. Ruchholtz S, Waydhas C, Lewan U, Pehle B, Taeger G, et al. (2004) Free abdominal fluid on ultrasound in unstable pelvic ring fracture: is laparotomy always necessary? J Trauma 57: 278-285.

25. Scialpi M, Scaglione M, Angelelli G, Lupattelli L, Resta MC, et al. (2004) Emergencies in the retroperitoneum: assessment of spread of disease by helical CT. Eur J Radiol 50: 74-83.

26. Wight J, Paisley S (2003) The epidemiology of inhibitors in haemophilia A: a systematic review. Haemophilia 9: 418-435.

27. White GC 2nd, Rosendaal F, Aledort LM, Lusher JM, Rothschild C, et al (2001) Definitions in hemophilia. Recommendation of the scientific subcommittee on factor VIII and factor IX of the scientific and standardization committee of the International Society on Thrombosis and Haemostasis. Thromb Haemost 85: 560.

28. Lawrence JS, Johnson JB (1941) The Presence of a Circulating AntiCoagulant in a Male Member of a Hemophiliac Family. Trans Am Clin Climatol Assoc 57: 223-231.

29. Schneiderman J, Rubin E, Nugent DJ, Young G (2007) Sequential therapy with activated prothrombin complex concentrates and recombinant FVIIa in patients with severe haemophilia and inhibitors: update of our previous experience. Haemophilia 13: 244-248.

30. Ingerslev J (2000) Efficacy and safety of recombinant factor VIIa in the prophylaxis of bleeding in various surgical procedures in hemophilic patients with factor VIII and factor IX inhibitors. Semin Thromb Hemost 26: 425-432.

31. Lusher J, Ingerslev J, Roberts H, Hedner U (1998) Clinical experience with recombinant factor VIIa. Blood Coagul Fibrinolysis 9: 119-128.

32. Lusher JM, Roberts HR, Davignon G, Joist JH, Smith H, et al. (1998) A randomized, double-blind comparison of two dosage levels of recombinant factor VIIa in the treatment of joint, muscle and mucocutaneous haemorrhages in persons with haemophilia A and B, with and without inhibitors. rFVIIa Study Group. Haemophilia, 1998. 4: 790-798.

33. Roberts HR, Monroe DM, White GC (2004) The use of recombinant factor VIIa in the treatment of bleeding disorders. Blood 104: 3858-3864.

34. Craddock CG Jr, Lawrence JS (1947) Hemophilia; a report of the mechanism of the development and action of an anticoagulant in two cases. Blood 2: 505-518.

35. DiMichele DM (2006) Inhibitor treatment in haemophilias A and B: inhibitor diagnosis. Haemophilia 12 Suppl 6: 37-41.

36. Frommeyer WB Jr., Epstein RD, Taylor FH (1950) Refractoriness in hemophilia to coagulation-promoting agents: whole blood and plasma derivatives. Blood 5: 401-420.

37. Åaguna P, Mital A (2012) Single higher dose of recombinant activated factor VII in the treatment of hemorrhages in patients with hemophilia complicated by inhibitors. Adv Clin Exp Med 21: 519-524.

38. Lenchik L, Dovgan DJ, Kier R (1994) CT of the iliopsoas compartment: value in differentiating tumor, abscess, and hematoma. AJR Am J Roentgenol 162: 83-86.

39. $\mathrm{Ng} \mathrm{HJ}$, Lee LH (2006) Recombinant activated clotting factor VII (rFVIIa) in the treatment of surgical and spontaneous bleeding episodes in hemophilic patients. Vasc Health Risk Manag 2: 433-440.

40. Gouw SC, Van Der Bom JG, Van Den Berg HM, Zewald RA, Ploos Van Amstel JK, et al. (2011) Influence of the type of F8 gene mutation on inhibitor development in a single centre cohort of severe haemophilia A patients. Haemophilia 17: 275-281.

41. Lusher JM, Lee CA, Kessler CM, Bedrosian CL; ReFacto Phase 3 Study Group (2003) The safety and efficacy of B-domain deleted recombinant factor VIII concentrate in patients with severe haemophilia A. Haemophilia 9: 38-49.

42. Orwig D, Federle MP (1989) Localized clotted blood as evidence of visceral trauma on CT: the sentinel clot sign. AJR Am J Roentgenol 153: 747-749.

43. Zissin R, Ellis M, Gayer G (2006) The CT findings of abdominal anticoagulant-related hematomas. Semin Ultrasound CT MR 27: $117-125$. 